\title{
Characteristics of Alluvial Diamonds from Bingara and Wellington, Eastern Australia
}

Davies, R. M. ${ }^{1}$, O'Reilly, S. Y.1 , Griffin, W. L. ${ }^{1,2}$

1. GEMOC National Key Centre, Macquarie University, Sydney, NSW, 2109, Australia

2. CSIRO Exploration and Mining, P. O. Box 136, North Ryde, NSW, 2113, Australia

The eastern margin of Australia hosts diamond deposits that occur in alluvium and in buried alluvium beneath Tertiary basalt flows. The primary source of the eastern Australian diamonds is at present unknown. Diamonds do not occur with any of the conventional diamond indicator minerals and source and host rocks remain unidentified. Because these diamonds occur in a Phanerozoic accretionary environment, distinct from Proterozoic and Archean cratonic domains west of the Tasman Line (Figure 1), their occurrence is considered enigmatic, and it raises questions as to whether all macro-diamonds originate from kimberlites or lamproites in Archean and Proterozoic cratons (see Griffin et al., 1998). The aim of this study is to characterise the eastern Australian diamonds and determine whether they differ from diamonds of conventional cratonic occurrences.

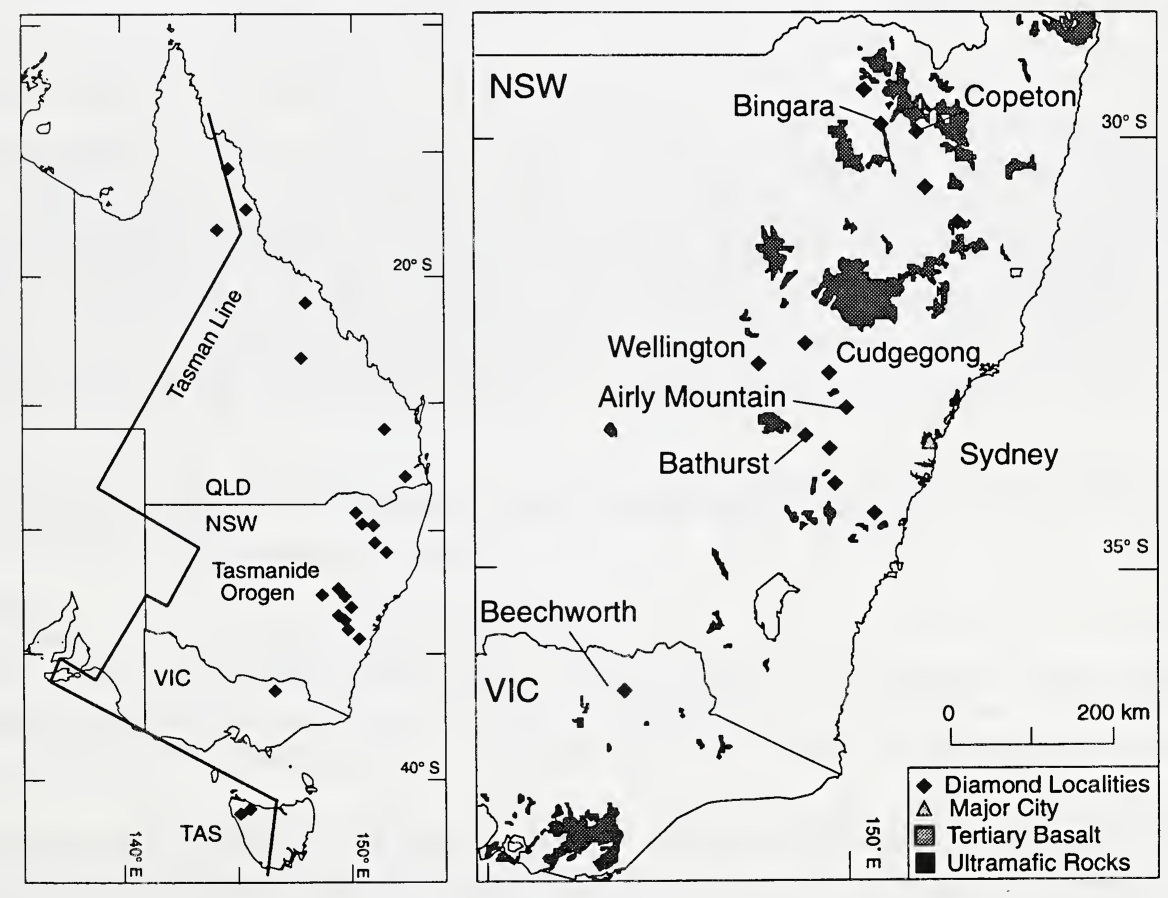

Figure 1. Maps of E. Australia showing distribution of major alluvial diamond deposits.

More than 1000 diamonds from alluvial deposits at Wellington and Bingara, New South Wales, Australia, have been characterised on the basis of their morphological features, mineral inclusion compositions, carbon isotopes, nitrogen content and aggregationstates, and internal structures. The 
diamonds are of two types, here termed Group A and B. At Wellington Group A and B occur in the ratio 4:1, while at Bingara the population is essentially of the $B$ type.

All diamonds are yellow, white or brown in colour. At both localities the diamonds average a weight of about $0.17 \mathrm{ct}$, with a range between 0.02 and $1.07 \mathrm{ct}$, but there are records of larger stones. The diamonds are characterised by polished forms that have been strongly rounded by resorption. Etch features compare to those of diamonds erupted by kimberlite and lamproites, indicative of diamond transport to the surface in a magma. Unique to Group B diamonds are large isolated frosted pits and strong deformation features. Mild abrasion is evident on most stones, and radiation damage is more common in the Group A diamonds, suggesting different alluvial histories for the two groups.

The compositions of syngenetic mineral inclusions indicate that the Group A diamonds formed in a dominantly peridotitic mantle volume; a small number of stones contain eclogitic inclusions. Olivine (Fo 92-95, mean 93) is the dominant inclusion; the range in $\mathrm{Mg}$ numbers suggests derivation from both lherzolitic and harzburgitic rocks (Meyer, 1987). Rare pentlandite and chromite also occur. The Group B diamonds have only eclogitic inclusions with the exception of one diamond containing olivine (Fo 89); the inclusion suite contains a wide range of diopside - omphacite clinopyroxenes (3 to $40 \% \mathrm{Jd}$ ), coesite, grossular-rich garnet (Gr 61 - 83\%), sphene and molybdenite. Sphene and molybdenite have not previously been recognised as syngenetic inclusions in diamond. Furthermore the extremely calcium rich compositions of the garnets and many of the clinopyroxenes are unique to this diamond inclusion suite.

Internal growth features also vary between groups. Group A diamonds have planar growth layers showing octahedral form that suggests they have grown in mostly stable conditions (Bulanova, 1995). In $25 \%$ of these diamonds, intermediate zones are truncated by one or more resorption episodes with overgrowths of octahedral layers. All diamonds show a late resorption episode that probably occurred in the emplacing magma. Nitrogen contents (measured from infra red absorbance spectra) of Group A diamonds are generally high (250 to $2500 \mathrm{ppm}$ ) and show a gradational decrease from core to rim. Corresponding IaB nitrogen aggregationranges from 6 to $42 \%$. A small group of Group A stones has low N contents (140 to 900 ppm) but high IaB aggregationstates (44$95 \%)$.

Growth structures in the Group B diamonds are complex (Davies et al., this volume). Diamonds with high $\mathrm{N}$ contents $(900-3000 \mathrm{ppm})$ have homogeneous structures and often contain trace amounts of carbonate and hydrogen. Low-nitrogen diamonds show evidence of unstable growth coinciding with deformation events with non-planar growth facets, some resorption, and displacement and brecciation of central structures that have annealed and show subsequent overgrowths. Rare sector growth and dendritic structures also occur. In these diamonds, central structures are nitrogen rich (ca $1000 \mathrm{ppm})$, and rim zones are nitrogen poor $(<100 \mathrm{ppm})$.

The group divisions are supported by carbon isotope measurements (Fig. 2). Group A diamonds have $\partial^{13} \mathrm{C}$ values that range between $-10 \%$ and $-3 \%$, within the world range for peridotite diamonds, and suggest a derivation from a homogenised mantle carbon source. Group B diamonds are ${ }^{13} \mathrm{C}$ enriched $\left(\partial^{13} \mathrm{C}=-5 \%\right.$ o to $+3 \%$ ), a signature that may suggest a crustal origin for the carbon; this is also supported by nitrogen isotope measurements (Cartigny, unpubl. results). 


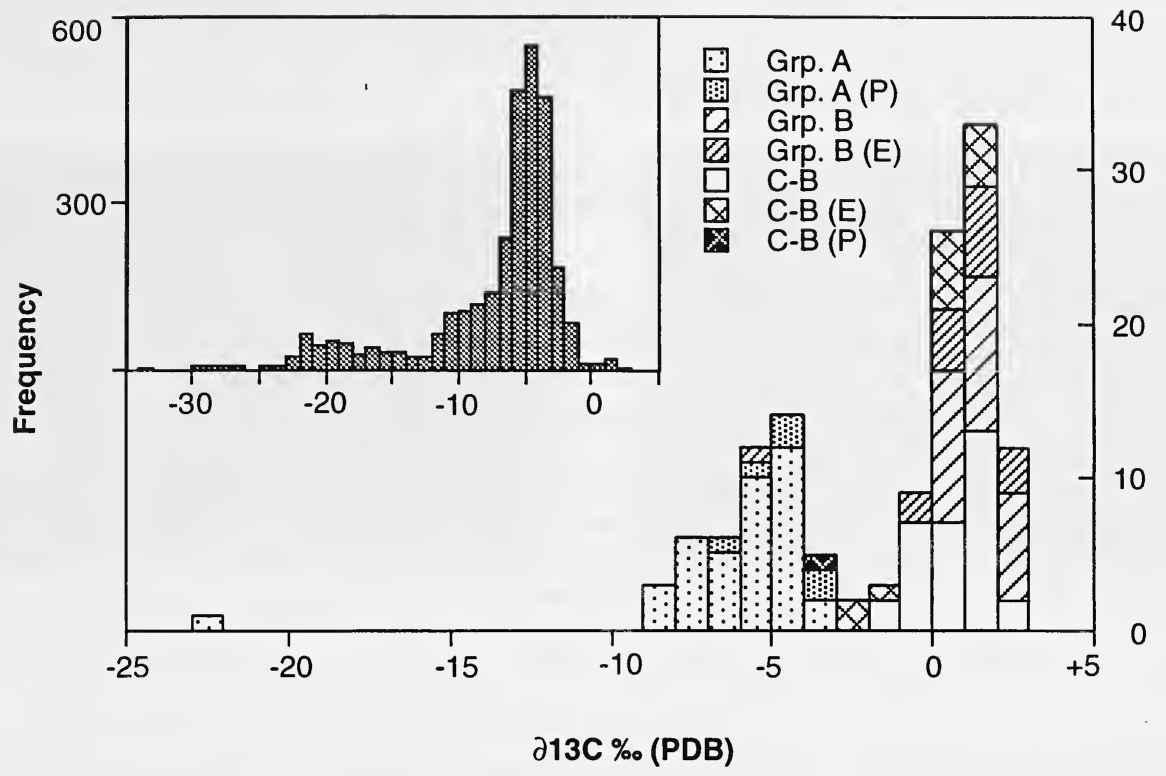

Figure 2. Carbon isotope compositions and distribution for diamonds from Groups $\mathrm{A}$ and $\mathrm{B}$, including samples of the peridotitic (P) and eclogitic (E) parageneses, compared to diamonds from Copeton-Bingara (C-B; Sobolev, 1984) and the world-wide range and distribution (inset; after van Heerden et al., 1995).

The characteristics of the Group B diamonds are consistent with formation in a subducted oceanic plate in which diamond has crystallised under low temperature-high pressure eclogite facies conditions in the diamond stability field. Rodingitisation of basaltic dikes in exposed peridotite prior to subduction, or mixing with Mg-carbonates, followed by subduction could account for the calcium rich inclusion suite, as well as the heavy carbon isotopic signatures (Griffin et al., 1998). The Group A diamonds may be derived from a more conventional source such as a cratonic Proterozoic lithosphere, and may have been shed from the craton west of the Tasman Line through alluvial reworking, as suggested by the greater incidence of radiation damage in this group. An eastern Australian derivation for these diamonds would imply the presence of slices of cratonic lithosphere beneath eastern Australia.

\section{References}

Bulanova, G. P., 1995, The formation of diamond: J. Geochem. Expl., 53, p. 1-23.

Griffin, W. L., O'Reilly, S. Y. and Davies, R. M., 1998, Subduction-related diamond deposits? constraints and possibilities: Rev. Econ. Geol., in press.

Meyer, H. O. A., 1987, Inclusions in Diamond: In: Mantle Xenoliths (P. H. Nixon, ed.), John Wiley and Sons, p. 501-522.

Sobolev, N. V., 1984, Crystalline inclusions in diamonds from New South Wales, Australia: In: Kimberlite Occurrence and Origin: A basis for conceptual models in exploration (J. E. Glover and P. G. Harris, eds.). The University of Western Australia, Publ. No. 8, p.213-226.

van Heerden, L. A., Gurney, J. J. and Deines, P., 1995, The carbon isotopic composition of harzburgitic, lherzolitic, websteritic and eclogitic paragenesis diamonds from southern Africa: a comparison of genetic models: Sth African J. Geol., 98, p. 119-125. 